\title{
Scaling and Assessment of an Evidence-Based Faculty Development Program for Promoting Active Learning Pedagogical Strategies
}

\section{Lydia Ross, Arizona State University}

Lydia Ross is a doctoral candidate and graduate research assistant at Arizona State University. Her research interests focus on higher education equity and access, particularly within STEM.

\section{Dr. Lindy Hamilton Mayled, Arizona State University}

Lindy Hamilton Mayled is the Director of Instructional Effectiveness for the Fulton Schools of Engineering at Arizona State University. She has a PhD in Psychology of Learning, Education, and Technology from Grand Canyon University. Her research and areas of interest are in improving educational outcomes for STEM students through the integration of active learning and technology-enabled frequent feedback. Prior to her role and Director of Instructional Effectiveness, she worked as the Education Project Manager for the NSF-funded JTFD Engineering faculty development program, as a high school math and science teacher, and as an Assistant Principal and Instructional \& Curriculum Coach.

\section{Prof. Stephen J Krause, Arizona State University}

Stephen Krause is professor in the Materials Science Program in the Fulton School of Engineering at Arizona State University. He teaches in the areas of introductory materials engineering, polymers and composites, and capstone design. His research interests include evaluating conceptual knowledge, misconceptions and technologies to promote conceptual change. He has co-developed a Materials Concept Inventory and a Chemistry Concept Inventory for assessing conceptual knowledge and change for introductory materials science and chemistry classes. He is currently conducting research on NSF projects in two areas. One is studying how strategies of engagement and feedback with support from internet tools and resources affect conceptual change and associated impact on students' attitude, achievement, and persistence. The other is on the factors that promote persistence and success in retention of undergraduate students in engineering. He was a coauthor for best paper award in the Journal of Engineering Education in 2013. Last year he received the ASEE Mike Ashby Outstanding Materials Educator Award.

\section{Dr. Eugene Judson, Arizona State University}

Eugene Judson is an Associate Professor of for the Mary Lou Fulton Teachers College at Arizona State University. He also serves as an Extension Services Consultant for the National Center for Women and Information Technology (NCWIT). His past experiences include having been a middle school science teacher, Director of Academic and Instructional Support for the Arizona Department of Education, a research scientist for the Center for Research on Education in Science, Mathematics, Engineering and Technology (CRESMET), and an evaluator for several NSF projects. His first research strand concentrates on the relationship between educational policy and STEM education. His second research strand focuses on studying STEM classroom interactions and subsequent effects on student understanding. He is a codeveloper of the Reformed Teaching Observation Protocol (RTOP) and his work has been cited more than 2200 times and he has been published in multiple peer-reviewed journals such as Science Education and the Journal of Research in Science Teaching.

\section{Prof. Keith D. Hjelmstad, Arizona State University}

Keith D. Hjelmstad is President's Professor of Civil Engineering in the School of Sustainable Engineering and the Built Environment at Arizona State University.

\section{Prof. James A Middleton, Arizona State University}

James A. Middleton is Professor of Mechanical and Aerospace Engineering and Director of the Center for Research on Education in Science, Mathematics, Engineering, and Technology at Arizona State University. For the last three years he also held the Elmhurst Energy Chair in STEM education at the University 
of Birmingham in the UK. Previously, Dr. Middleton was Associate Dean for Research in the Mary Lou Fulton College of Education at Arizona State University, and Director of the Division of Curriculum and Instruction. He received his Ph.D. in Educational Psychology from the University of Wisconsin-Madison in 1992, where he also served in the National Center for Research on Mathematical Sciences Education as a postdoctoral scholar.

\section{Prof. Robert J Culbertson, Arizona State University}

Robert J. Culbertson is an Associate Professor of Physics. Currently, he teaches introductory mechanics and electrodynamics for physics majors and a course in musical acoustics, which was specifically designed for elementary education majors. He is director of the ASU Physics Teacher Education Coalition (PhysTEC) Project, which strives to produce more and better high school physics teachers. He is also director of Master of Natural Science degree program, a graduate program designed for in-service science teachers. He works on improving persistence of students in STEM majors, especially under-prepared students and students from under-represented groups.

\section{Dr. Casey Jane Ankeny, Northwestern University}

Casey J. Ankeny, PhD is an Assistant Professor of Instruction at Northwestern University. Casey received her bachelor's degree in Biomedical Engineering from the University of Virginia in 2006 and her doctorate degree in Biomedical Engineering from Georgia Institute of Technology and Emory University in 2012 where she studied the role of shear stress in aortic valve disease. Currently, she is investigating cyberbased student engagement strategies in flipped and traditional biomedical engineering courses. She aspires to understand and improve student attitude, achievement, and persistence in student-centered courses.

\section{Dr. Ying-Chih Chen, Arizona State University}

Ying-Chih Chen is an assistant professor in the Division of Teacher Preparation at Mary Lou Fulton Teachers College at Arizona State University in Tempe, Arizona.

His research takes two distinct but interrelated paths focused on elementary students' learning in science and engineering as well as in-service science teachers' professional development. The first focus involves how language as a learning tool improves students' conceptual understandings, literacy, and representation competencies in science. His second research focus is on how in-service teachers develop their knowledge for teaching science and engineering in argument-based inquiry classrooms. This research is aimed at developing measures of teachers' Pedagogical Content Knowledge (PCK) for adopting the argumentbased inquiry approach, as well as developing tools to capture the interactive nature of PCK.

\section{Kara L. Hjelmstad, Arizona State University}

Kara Hjelmstad has currently worked as a faculty associate and student teacher supervisor for Mary Lou Fulton Teachers College at Arizona State University. After earning a BA degree in elementary education and an M.Ed. degree in curriculum and instruction, she spent twelve years teaching K-5 and enrichment at the elementary level.

In 2010, Kara began teaching courses and supervising student teachers at ASU. Kara is TAP certified, an evaluation system designed to improve teaching effectiveness and student achievement. The TAP evaluation involves classroom observations, coaching, and feedback/reflection for professional growth. Kara has worked with $60+$ student teachers in various subjects at the pre-K through 12 th grade level, and conducted over 100 TAP classroom observations.

Since the fall of 2016, Kara has been working with the JTFD Project, an NSF grant working to improve active learning in engineering education. She has completed 300 RTOP classroom observations in ASU engineering courses (civil, environmental, construction, chemical, aero/mechanical, materials, transportation, and biomedical engineering). The RTOP or Reformed Teaching Observation Protocol, is a rubric designed to assess student centered learning practices in math and science. Kara also provided instructional coaching for 37 engineering faculty grant participants, after their teaching observations. 


\section{Mrs. Kristi Glassmeyer, Arizona State University}

Kristi is a Ph.D student in Educational Policy and Evaluation at Arizona State University.

\section{Sarah Hoyt, Arizona State University}

Sarah Hoyt is currently the Education Project Manager for the NSF-funded JTFD Engineering faculty development program. Her educational background includes two Master's degrees from Grand Canyon University in Curriculum and Instruction and Education Administration. Her areas of interest are in student inclusion programs and creating faculty development that ultimately boost engagement and performance in students from lower SES backgrounds. Prior to her role as project manager, Sarah worked as the SEI Coordinator for a local high school and has also developed an inclusion program for Migrant and Immigrant students that utilized co-teaching and active learning as keystones of the program. She began her educational career as a high school teacher, teaching courses in English, math, and science. 


\title{
Scaling and Assessment of an Evidence-Based Faculty Development Program for Promoting Active Learning Pedagogical Strategies
}

\begin{abstract}
This complete research-based paper explores a successful faculty development program aimed at increasing awareness and use of evidence-based pedagogical strategies among engineering faculty across multiple disciplines. Research demonstrates that student-centered, or active learning, strategies promote greater student learning and achievement. Despite this evidence, however, the majority of engineering faculty still employ teacher-centered strategies, or the traditional lecture method, in their classrooms. Therefore, there is a strong need for professional development to increase faculty awareness and use of student-centered teaching strategies.
\end{abstract}

The setting for this professional development program, which is funded through NSF's Improving Undergraduate STEM Education (IUSE) program, is a large, public university in the southwest United States. This large-scale professional development program utilizes a train-thetrainer model where faculty across seven engineering disciplines participate in eight biweekly workshops and six biweekly community of practice (CoP) sessions to engage faculty over a oneyear period. In this paper, we discuss the creation and scaling of the faculty development program. In particular, we describe the structure and management of the program, strategies and topics covered, assessment/evaluation, and key takeaways.

This professional development program utilizes a train-the-trainer model, where two people from different engineering disciplines are recruited to become disciplinary leader pairs (DLPs). The DLPs go through the program (8 workshops in the fall semester and 6 workshops in the spring semester) under the direction of the project leaders/PIs. Then the following year, the DLPs become the "trainers," where they lead the workshops and community of practice sessions for a group of faculty, ranging from 8 to 15 people from their own discipline. The program consists of 8 biweekly workshops, which covers Bloom's taxonomy, learning objectives, interactive classes, active and cooperative learning, muddiest points, tech tools, and fostering inclusive learning environments. The following semester, faculty participate in semi-structured CoP sessions to discuss challenges/successes of implementing active learning strategies and to share ideas.

The professional development program was evaluated through multiple methods, including surveys from faculty, classroom observations, and student achievement data. Data collection and instruments are discussed in greater detail in this paper. Key highlights include a 13\% in average use of active learning strategies by faculty after participating in the program. Additionally, we observed an average increase of $34 \%$ in reported increase in use of formative feedback pedagogical practices after the program. All of the faculty participants reported that the professional development program would be valuable to future instructional practice and career success. All participants also reported that they would recommend this professional development program to their colleagues. This paper describes the creation and scaling, structure and implementation, and assessment of a large-scale, successful professional development program. We conclude by discussing key takeaways and lessons learned from the professional development program. 


\section{Introduction \& Background}

Active learning, or student-centered teaching practices, engage key course/subject concepts and materials through an interactive and adaptive manner in the classroom. Research demonstrates that active learning pedagogical practices are more effective for promoting student learning and achievement. After conducting a thorough review of the literature, Prince concluded that engineering faculty should consider incorporating new instructional practices and techniques, especially active learning principles, into their classroom, based on compelling evidence in the literature base which suggests that student-centered teaching promotes greater student learning [1]. In a separate review of the literature, Freeman et al., conducted a meta-analysis of 225 studies that examined instructional practices in undergraduate STEM classes and found that students had $6 \%$ greater performance on concept inventories in active learning classrooms; whereas students enrolled in a traditional lecture class were 1.5 times more likely to fail [2]. Ultimately, there is compelling evidence which demonstrates the efficacy of active learning teaching practices with undergraduate STEM classes.

Despite this evidence in support of active learning, the predominant form of teaching in undergraduate engineering classes has long been the lecture, or teacher-centered instruction [3, 4]. However, the challenge then is shifting classroom instruction from lecture style information transfer to engaging and interactive student-centered pedagogical practices. But, simply providing information about active learning teaching strategies with faculty is not enough to create sustainable shifts in teaching practices. Rather, it is important to facilitate processes where faculty can engage in ongoing and deep learning about student-centered teaching strategies, particularly through professional development programs $[5,6]$.

In a previous professional development program, seven faculty members in the materials engineering discipline collaborated over a four-year period [7]. During the JTF program, participating faculty engaged in discussions and activities around student-centered learning. Much of the program was based on the findings of the book How People Learn [8]. Through this professional development program, nearly all participants reported that their pedagogical practices shifted substantially as a result of their participation in the program. They also observed positive effects of active learning practices in the classroom with increased grade point average and a reduction in D's and E's awarded by more than 50\% [9]. The JTFD program developed out of the JTF pedagogy, but expanded to include faculty across multiple engineering disciplines.

This paper discusses a large-scale professional development program at a large college of engineering at a university in the southwestern United States. The program was funded through the National Science Foundation's (NSF) Improving Undergraduate Science Education (IUSE) program. The JTFD professional development program engages faculty across seven engineering disciplines: aerospace, biomedical, chemical, civil, construction, materials, and mechanical. The year-long professional development program aims to increase the use of active learning strategies in engineering classrooms by increasing awareness of student-centered teaching practices and creating opportunities for faculty to discuss and explore implementing active learning instructional practices in the classroom. In this paper, we describe the program structure, program evaluation methodology, and a summary of data analysis and evaluation for the JTFD 
professional development program. To learn more about the JTFD project and access training materials visit www.jtfdproject.org/.

\section{JTFD Program Structure}

The JTFD program was structured so that each faculty group would participate in a series of 8 biweekly workshops in the fall semester. In the spring semester, faculty groups would attend 6 communities of practice sessions. In the following academic year, faculty could attend voluntary continuing communities of practice sessions, which were more informal and focused on discussing innovations in the classroom. The project investigator team developed all materials for the program, including workshop materials, readings, discussion guides, and activities.

The JTFD program utilized a "train-the-trainer" model [10] to disseminate information about student-centered teaching strategies. We first recruited 8 faculty who became the disciplinary leader pairs (DLPs) from four engineering disciplines. The first group of DLPs came from aerospace, civil, construction, and mechanical engineering disciplines. Then, the project investigator team facilitated the JTFD program for the DLPs. The following academic year, the DLPs trained their own groups of faculty from their own engineering disciplines. This process was repeated again with a second group of faculty who became the Cohort 2 Tier 1 DLPs. These DLPs came from biomedical, chemical, and materials science engineering disciplines.

Throughout the program, the project investigator team was available to support and assist the DLPs throughout their implementations of the JTFD program. A detailed presentation of the project schedule is presented in table 1 , below.

Table 1

Project Overview and Schedule

\begin{tabular}{|c|c|c|c|c|}
\hline & $\begin{array}{l}\text { Cohort } 1 \text { Tier } 1 \\
\text { Disciplinary Leader } \\
\text { Pairs (DLPs) }\end{array}$ & $\begin{array}{l}\text { Cohort } 1 \text { Tier } 2 \\
\text { Disciplinary } \\
\text { Faculty Groups } \\
\text { (DFGs) }\end{array}$ & $\begin{array}{l}\text { Cohort } 2 \text { Tier } 1 \\
\text { Disciplinary } \\
\text { Leader Pairs } \\
\text { (DLPs) }\end{array}$ & $\begin{array}{l}\text { Cohort } 2 \text { Tier } 2 \\
\text { Disciplinary } \\
\text { Faculty Groups } \\
\text { (DFGs) }\end{array}$ \\
\hline $\begin{array}{l}\text { Year 1 } \\
\text { Fall } 2015- \\
\text { Spring } 2016\end{array}$ & $\begin{array}{l}\text { Being trained by } \\
\text { Project Leaders \& } \\
\text { classroom } \\
\text { implementation }\end{array}$ & & & \\
\hline $\begin{array}{l}\text { Year } 2 \\
\text { Fall } 2016- \\
\text { Spring } 2017\end{array}$ & $\begin{array}{l}\text { Teach Sessions to } \\
\text { Tier } 2 \text { DFGs }\end{array}$ & $\begin{array}{l}\text { Being trained by } \\
\text { Cohort } 1 \text { Tier } 1 \\
\text { DLPs }\end{array}$ & $\begin{array}{l}\text { Being trained } \\
\text { by project } \\
\text { leaders \& } \\
\text { classroom } \\
\text { implementation }\end{array}$ & \\
\hline $\begin{array}{l}\text { Year } 3 \\
\text { Fall } 2017- \\
\text { Spring } 2018 \\
\end{array}$ & $\begin{array}{l}\text { Facilitate CoPs } \\
\text { Ongoing assessment }\end{array}$ & Ongoing assessment & $\begin{array}{l}\text { Teach sessions to } \\
\text { Cohort } 2 \text { Tier } 2 \\
\text { DFGs }\end{array}$ & $\begin{array}{l}\text { Being trained by } \\
\text { Cohort } 2 \text { Tier } 1 \\
\text { DLPs }\end{array}$ \\
\hline $\begin{array}{l}\text { Year } 4 \\
\text { Fall } 2018- \\
\text { Spring } 2019 \\
\end{array}$ & Ongoing assessment & Ongoing assessment & $\begin{array}{l}\text { Facilitate CoPs } \\
\text { Ongoing assessment }\end{array}$ & $\begin{array}{l}\text { Ongoing } \\
\text { assessment }\end{array}$ \\
\hline
\end{tabular}




\section{JTFD Program Content}

\section{Workshops}

During the fall semesters faculty attended hour long bi-weekly workshops focused on evidencebased instructional strategies, rooted in JTF pedagogical practices. The workshop sessions connected research to practice. First, the leadership team determined the topics for each workshop. Then the project leadership created a time management schedule. The project leadership team then selected readings, websites, videos, or other content for each session. This information was then utilized to develop PowerPoints presentations.

A cohesive "workshop" plan was developed for each session, which then went through a thorough review process. Each workshop consisted of an introduction, brief discussion of homework results, a mini-lecture covering the main topic for that session, then one or two facilitated activities (ie. breakout discussions, think-pair-share, active learning activities), and concluded with a report back from group work or a concluding conversation. The workshops covered the following topics:

1. Introduction to active learning and disciplinary communities of practice

2. Bloom's taxonomy and writing effective learning objectives

3. Pedagogies of engagement I: Making class sessions more interactive

4. Pedagogies of engagement II: Implementing active learning in the classroom

5. Pedagogies of engagement III: cooperative learning - structured teams

6. Motivation and learning

7. Promoting inclusive practices in the classroom

8. Muddiest points and other tech tools: Facilitating course innovation

\section{Communities of Practice (CoPs)}

In the spring semester after the workshops, the faculty groups participated in Communities of Practice (CoP) discussion sessions. Topics for the CoP sessions were determined based off of faculty input. The project team developed materials, which included a short refresher PowerPoint, handout of key ideas, and a facilitated discussion guide with critical open-ended questions. These sessions were less formal than the workshops, but employed a semi-structured layout to encourage flexibility, while also staying focused on the topic being discussed. The communities of practice sessions covered the following topics:

1. Opportunities and issues in implementation of Bloom's taxonomy and active learning

2. Assessing student-centered learning vs. instructor-centered teaching

3. Implementation of tech tools and impact of summative and formative assessment

4. Discussion of observations of active learning classrooms of project leaders

5. Implementation of cooperative learning and motivation

6. Implement wrap-up of faculty beliefs, instructor role in classroom \& value of CoPs 


\section{Continuing Communities of Practice (CCoPs)}

Originally faculty participation was intended to end at the conclusion of the CoP sessions in the spring semester. However, due to interest from faculty participants, the project investigator team expanded the JTFD program to include continuing communities of practice (CCoPs). The $\mathrm{CCoP}$ component of the program comprised a second, optional year of program participation. There were 8 total $\mathrm{CCoP}$ sessions across the fall and spring semesters. Topics reinforced previously covered areas from JTFD workshops, and followed a recent book by Brent and Felder Teaching and learning STEM: A practical guide [11]. The CCoP sessions were facilitated by one of the project team leaders. The topics for the $\mathrm{CCoP}$ session included:

1. Writing learning objectives

2. Planning courses

3. Class sessions

4. Elements of effective instruction

5. Active learning

6. Teaching with technology

7. Evaluating knowledge, skills, and understanding (part I - designing and grading tests)

8. Evaluating knowledge, skills, and understanding (part II - evaluating assignments)

Due to continued interest, the project investigator team further extended the CCoPs. Faculty members were invited to participate in continued CCoPs for a second year. These sessions followed the same informal format as the first year of $\mathrm{CCoPs}$, and were led by two project team leaders. We hope to continue the implementation of these CCoPs in the future.

Ultimately, the principal investigator team created an engaging, dynamic, and flexible professional development program. Through the program, faculty participated in a year-long program of workshops and communities of practice, where they engaged with other engineering faculty program participants and the principal investigator team about implementing active learning teaching strategies in the classroom.

\section{Sample \& Program Participants}

In total, 82 faculty members participated in the JTFD professional development program. Table 2 , below, shows a breakdown of faculty participation by discipline and year.

Table 2

JTFD Faculty Participants

\begin{tabular}{|c|l|c|}
\hline Cohort & \multicolumn{1}{|c|}{ Discipline } & $\begin{array}{c}\text { Number of Faculty } \\
\text { Participants }\end{array}$ \\
\hline $\begin{array}{c}\text { Cohort One } \\
(15-16)\end{array}$ & Disciplinary Leader Pairs for cohort one & 8 \\
\hline \multirow{2}{*}{$\begin{array}{c}\text { Cohort One } \\
(16-17)\end{array}$} & Civil & 13 \\
\cline { 2 - 3 } & Construction & 9 \\
\cline { 2 - 3 } & Aerospace \& Mechanical & 13 \\
\hline
\end{tabular}




\begin{tabular}{|c|l|c|} 
& Disciplinary Leader Pairs for cohort two & 6 \\
\hline \multirow{3}{*}{$\begin{array}{c}\text { Cohort Two } \\
(17-18)\end{array}$} & Biomedical & 18 \\
\cline { 2 - 3 } & Chemical & 7 \\
\cline { 2 - 3 } & Materials & 8 \\
\hline
\end{tabular}

For the first cohort, we had a $100 \%$ retention rate with all faculty successfully completing both workshops and communities of practice. Cohort two had a 91\% retention rate, with 31 of the 34 faculty members completing the workshops and communities of practice.

In this paper, the program evaluation results are presented for all program participants across all three years of the program. Only faculty who filled out pre- and post-surveys are included in the analysis. Due to challenges with completion rates, the number of completed surveys vary across each survey, so the number included for each analysis varies, and is noted below.

\section{Data Sources \& Analysis}

Program evaluation focused on four major areas: (a) shifts in awareness of, attitudes towards, and reported use of active learning pedagogical practices, (b) changes in instructional practices, and (c) effectiveness of communities of practices sessions, and (d) satisfaction with the JTFD program. To measure these four areas, we administered a series of surveys and conducted classroom observations.

These data were collected at three points across the academic year: before the start of the program (pre), between the fall and spring semesters (mid), and at the end of the program (post). Due to differing completion rates of faculty members for each survey, the number of responses varies across time points and surveys.

\section{Education Research Awareness \& Use Survey}

The first survey administered was the Education Research Awareness \& Use (ERAU) survey, which measures awareness and use of various pedagogical practices. The awareness items assessed respondents' awareness or familiarity with different teaching strategies, as well as research on these concepts, awareness on a 4-point Likert scale from very unfamiliar to very familiar. It also measured faculty members' self-reported use of four specific teaching strategies on a 4-point Likert scale from never to frequently.

To assess for changes in awareness, responses were categorized into two groups: familiar (those who responded with familiar or very familiar) or unfamiliar (unfamiliar or very unfamiliar responses). We then calculated the percentage of faculty that fell into the familiar group before and after the professional development program. Table 3 shows the average percentage change in awareness of the pedagogical topics/constructs across faculty members' participation in the program. All of the changes were significant $(p<0.05)$. Awareness of student motivation shifted the most, with a $37 \%$ increase in awareness. Professional learning communities and instructional design were also areas with big shifts in awareness (at 34\% and 30\%, respectively). The area with the least change in awareness was learning objectives, at a $13 \%$ increase. This finding is not as surprising since $85 \%$ of faculty participants were familiar learning objectives at the start of the 
professional development program. Overall, these findings indicate positive shifts in increased awareness of education research for the faculty participants in the JTFD program.

Table 3

Change in Faculty Awareness of Education Research

\begin{tabular}{|l|c|c|c|}
\hline \multirow{2}{*}{\multicolumn{1}{|c|}{ Construct }} & \multicolumn{2}{|c|}{ Percent of Faculty Within Top Two Items of } \\
& \multicolumn{2}{|c|}{ the Likert Scales } \\
\cline { 2 - 4 } & $(\mathrm{n}=66)$ & $\begin{array}{c}\text { Post } \\
\text { Change in } \\
\text { Percentage Points } \\
\text { from Pre to Post }\end{array}$ \\
\cline { 2 - 4 } Effective Teaching & $65 \%$ & $88 \%$ & $23 \%$ \\
\hline Instructional Design & $39 \%$ & $69 \%$ & $30 \%$ \\
\hline How People Learn & $59 \%$ & $79 \%$ & $20 \%$ \\
\hline Active Learning Research & $62 \%$ & $85 \%$ & $23 \%$ \\
\hline Teams & $71 \%$ & $92 \%$ & $21 \%$ \\
\hline Student Motivation & $42 \%$ & $79 \%$ & $37 \%$ \\
\hline Objectives & $85 \%$ & $98 \%$ & $13 \%$ \\
\hline Bloom's & $65 \%$ & $88 \%$ & $23 \%$ \\
\hline $\begin{array}{l}\text { Professional Learning } \\
\text { Communities }\end{array}$ & $37 \%$ & $71 \%$ & $34 \%$ \\
\hline
\end{tabular}

We then assessed for shifts in reported use of various teaching strategies, following the same analytical techniques as used with the awareness items. The percentage of participants that fell into the top-two items of the Likert scale were categorized into a frequent users group. The change in average percentage is reported in table 4 . There was a $34 \%$ increase in average reported use of Bloom's taxonomy, which aligns with key content of the professional development program. Cooperative learning was another area with a great increase in reported use, at $17 \%$. Active learning and objectives had lower reported average increase in use (at $6 \%$ each), which is likely due to the fact that faculty reported frequent use of both of these strategies when they started the program (at 92\%). In fact, nearly all respondents (98\%) reported using both active learning strategies and learning objectives at the end of the JTFD program.

Table 4

Change in Faculty Use of Teaching Strategies

\begin{tabular}{|l|c|c|c|}
\hline \multirow{2}{*}{ Construct } & Percent of Faculty Within Top Two Items of the Likert Scales \\
\cline { 2 - 4 } & Pre & Post & $\begin{array}{c}\text { Change in Percentage } \\
\text { Points from Pre to Post }\end{array}$ \\
\cline { 2 - 4 } & $(\mathrm{n}=66)$ & $(\mathrm{n}=46)$ & $17 \%$ \\
\hline Cooperative Learning & $83 \%$ & $100 \%$ & $6 \%$ \\
\hline Active Learning & $92 \%$ & $98 \%$ & $6 \%$ \\
\hline Objectives & $92 \%$ & $98 \%$ & 6 \\
\hline
\end{tabular}




\begin{tabular}{|l|l|l|l|} 
Bloom's Taxonomy & $51 \%$ & $85 \%$ & $34 \%$ \\
\hline
\end{tabular}

\section{Value, Expectancy, and Cost for Testing Educational Reforms Survey (VECTERS)}

The Value, Expectancy, and Cost for Testing Educational Reforms Survey (VECTERS) was designed by members of the project team to assess faculty dispositions towards and use of specific active learning strategies [12]. The instrument focused on three particular active learning strategies: (a) formative feedback to adjust instruction, (b) integrating real-world applications, and (c) facilitating student-to-student discussions in class. VECTERS measures dispositions towards the active learning strategies in terms of three specific constructs:

Value: The construct of value is closely related to benefit. The value items measured if respondents felt whether each strategy was beneficial or detrimental for both students and the instructor.

Expectancy: Expectancy items measured what respondents' believed would happen in the learning environment when each strategy was implemented. These items focused on whether respondents' believed the outcome would be successful or not. The expectancy items focused on three specific areas for reasons of success: students' abilities, instructor capabilities, and physical setup of the classroom.

Cost: The construct of cost measures perceived expenses for implementing each strategy in the classroom. Specifically, these items focused on respondents' thoughts regarding preparation time, use of teaching assistants, and required effort for incorporating each strategy in the classroom.

The VECTERS instrument comprised 11 value items, 10 expectancy items, and 5 cost items, for a total of 26 items to measure dispositions towards the three strategies. Respondents indicated their level of agreement to a series of statements on a 4-point Likert scale from strongly disagree to strongly agree. Lastly, there were two items that measured respondents' current use and planned future use of the three strategies on a 4-point Likert scale from not at all to entirely. Individuals with greater value, expectation of success, and lower perceived costs are more likely to implement that pedagogical practice in the classroom.

To examine shifts in faculty participants' attitudes and use of the student-centered teaching, we first calculated average scores for expectancy, value, cost, current use, and future use for each of the three active learning strategies. Then we calculated the percentage change in average from the pre- to post-period. A summary of this information is presented in Table 5. 
Table 5

Percent change in VECTERS constructs from fall (pre) to spring (post) semester

\begin{tabular}{|l|c|c|c|}
\hline Construct & $\begin{array}{c}\text { Formative } \\
\text { Feedback }\end{array}$ & $\begin{array}{c}\text { Real-World } \\
\text { Applications }\end{array}$ & $\begin{array}{c}\text { Student-to-Student } \\
\text { Discussions }\end{array}$ \\
\hline Expectancy & $12 \%^{*}$ & $0 \%$ & $2 \%$ \\
\hline Value & $7 \% *$ & $7 \% *$ & $5 \%$ \\
\hline Cost & $0 \%$ & $-11 \% *$ & $1 \%$ \\
\hline Current Use & $34 \% *$ & $2 \%$ & $12 \%$ \\
\hline Future Use & $18 \% *$ & $1 \%$ & $5 \%$ \\
\hline
\end{tabular}

$* p<.05$

The greatest gains were made in formative feedback. Respondents had a $12 \%$ increase in expectation of success for formative feedback. There was a $7 \%$ average change in value. What was more interesting was that respondents reported a 34\% average increase in current use of and an $18 \%$ increase in planned future use of the strategy. Surprisingly, there was no shift in perceived cost of the strategy. So though participants did not view formative feedback as less costly, they still planned to implement it more into their classrooms. For real-world applications, there was not a significant shift in expectation of success. However, respondents had an average increase of $7 \%$ for value of the strategy, and an $11 \%$ decrease in perceived cost of implementing real-world applications in the classroom. There were no significant shifts in current or planned future use of the strategy. Somewhat unexpected was the lack of change for expectancy, value, cost, and current/future use of student-to-student facilitated discussions. Overall, participants had significant gains in dispositions towards formative feedback and real-world applications.

\section{Reformed Teaching Observational Protocol (RTOP)}

Since self-reported use of teaching strategies can be biased, it was important to conduct classroom observations to be able to determine and characterize actual classroom practices before and after the professional development program. Classroom observations were conducted by trained observers at three time points (pre-, mid-, and post-professional development program). Each time point was comprised of two distinct observations for improved validity.

Classroom observations were conducted using the Reformed Teaching Observational Protocol (RTOP). The RTOP quantifies the extent to which faculty utilize student-centered teaching strategies in the classroom [13 - 15]. The RTOP has five dimensions (each of which has five items). Observers rate faculty members on a 5-point Likert scale for each item, for a total possible score of 100 points per classroom observation. The five dimensions are:

Lesson design \& implementation: These items assessed structure and delivery of class materials. For example, one item measures whether instructors' draw on prior knowledge of students and the role of students in the learning process.

Propositional knowledge (content): This construct examines how course material is presented during the class session. For instance, these items focus on the subject matter being taught, and the ways in which the instructor includes key concepts. 
Procedural knowledge (content): These items measure how students engage with course materials. Specifically, these items are focused on assessing the ways that students talk about or characterize the phenomena being taught in the class and whether they are reflective about their learning in the course.

Communicative interactions (culture): The communicative interactions section focuses on the types of interactions that occur in the classroom. These items examine if classroom culture is inclusive and what types of communication are facilitated/encouraged in the class.

Student-teacher relationships (culture): This final construct examines the relationship between students and teachers in the classroom. For example, one item focuses on whether the teacher encouraged active participation in the classroom.

Results from the RTOP were analyzed to determine changes of faculty teaching practices, before, during, and after participation in the JTFD program. A distribution of RTOP scores before, during, and after the professional development program is presented in table 6, below. In general, the distribution of scores increased from pre to mid to post. The minimum RTOP score at the start of the professional development program was a 30.50, which increased to 34.50 at the mid-way point, and was 36 at the post-observation. The maximum score also increased from 92 (pre) to 95 (mid) to 97.5 (post). The mean was the same from the pre- to mid-time points. However, there was a notable increase in the average RTOP score across the professional development program (58.4 at the pre to 66.5 at the post).

Table 6

Distribution of RTOP Scores

\begin{tabular}{|l|l|l|l|}
\hline & Pre & Mid & Post \\
\hline Minimum & 30.50 & 34.50 & 36.00 \\
\hline Lower Quartile & 45.81 & 46.50 & 56.00 \\
\hline Mean & 58.44 & 58.34 & 66.50 \\
\hline Upper Quartile & 71.50 & 66.06 & 78.50 \\
\hline Maximum & 92.00 & 95.00 & 97.50 \\
\hline
\end{tabular}

To assess if these changes were significant, a series of paired-samples t-tests were conducted to compare the average RTOP score at various time-points. The results of the t-tests are presented, along with the average change in RTOP score, in table 7, below.

Table 7

Changes in Total RTOP Scores

\begin{tabular}{|l|c|c|}
\hline Time Period & Average Change & $\begin{array}{l}\text { Average Percent } \\
\text { Change }\end{array}$ \\
\hline Pre to Mid & 1.51 & $2.58 \%$ \\
\hline
\end{tabular}




\begin{tabular}{|l|l|l|}
\hline Mid to Post & $7.36^{*}$ & $12.46 \%$ \\
\hline Pre to Post & $7.50^{*}$ & $12.68 \%$ \\
\hline
\end{tabular}

${ }^{*} p<.05$

There was a small increase in average RTOP score (1.51 points) from pre to post, which amounted to a $3 \%$ increase. However, this change was not significant. There was a significant change from the mid-way observation to the post-observation (7.36 points), which was a $12.5 \%$ increase in use of active learning strategies in the classroom. There also was a $12.7 \%$ increase in use of active learning from the start of the program to the end of the program. These findings indicate that the majority of shifts in instruction occurred during the spring semester of the year that faculty participated in the JTFD professional development program.

\section{Communities of Practice}

To assess the Communities of Practice (CoPs) sessions, a short survey called the CoP Minute Surveys (CoPMS) were administered at the end of each CoP session. These surveys were short and asked faculty to respond to 3 statements on a 5-point Likert scale ranging from strongly disagree to strongly agree. The average score on each CoPM item is reported in table 8, below. As a reminder, the topics for each CoP session were:

1. Opportunities and issues in implementation of Bloom's taxonomy and active learning

2. Assessing student-centered learning vs. instructor-centered teaching

3. Implementation of tech tools and impact of summative and formative assessment

4. Discussion of observations of active learning classrooms of project leaders

5. Implementation of cooperative learning and motivation

6. Implement wrap-up of faculty beliefs, instructor role in classroom \& value of CoPs

Table 8

Average CoP survey scores, by session and total

\begin{tabular}{|l|c|c|c|c|c|c|c|}
\hline & \multicolumn{7}{|c|}{ Session Number } \\
\hline \multicolumn{1}{|c|}{ Statement } & 1 & 2 & 3 & 4 & 5 & 6 & Total \\
\hline $\begin{array}{l}\text { The topics discussed in this } \\
\text { session were relevant and } \\
\text { helpful to my teaching practice. }\end{array}$ & 4.5 & 4.4 & 4.5 & 4.55 & 4.35 & 4.65 & 4.6 \\
\hline $\begin{array}{l}\text { The topics discussed provided } \\
\text { me with new ideas for } \\
\text { implementation and/or } \\
\text { reaffirmed strategies I am } \\
\text { currently implementing. }\end{array}$ & 4.35 & 4.25 & 4.35 & 4.45 & 4.25 & 4.5 & 4.5 \\
\hline $\begin{array}{l}\text { The discussions and community- } \\
\text { building with other faculty is } \\
\text { valuable. }\end{array}$ & 4.6 & 4.5 & 4.65 & 4.7 & 4.55 & 4.75 & 4.6 \\
\hline
\end{tabular}

The scores were similar across all of the sessions. For the first item, which assessed if the CoP topics were relevant and helpful, there was an average score of 4.6 across all six CoP sessions. In 
general, faculty reported that the topics discussed during the CoP sessions were relevant and helpful. This was expected since faculty participants were able to give suggestions about the CoP topics, which were utilized in determining the final agenda of $\mathrm{CoP}$ topics. For the second item, there was an average score of 4.5, indicating that the topics discussed during the CoP sessions provided faculty with helpful ideas for implementation of teaching strategies. Lastly, faculty reported that discussions and community-building with other faculty during the CoP sessions were valuable (average of 4.6 across all sessions).

As previously mentioned, many faculty were interested in continued engagement with the JTFD program, so we established informal, optional continuing communities of practice (CCoPs) for the year after formal program participation. There were $8 \mathrm{CCoP}$ sessions across the entire academic year (four in the fall and four in the spring). In order to keep these sessions informal, and to encourage future participation, we did not track attendance or administer surveys to gain formal feedback for these sessions. A range of $7-15$ faculty attended each session. We received positive feedback from faculty across the CCoP sessions.

In general, the findings from this analysis suggest that the JTFD program was successful in creating sustainable communities of practice, not only with the formal CoP sessions, but also through CCoPs and ongoing conversations between faculty participants and the project investigator team.

\section{Satisfaction with JTFD Program}

At the end of the last community of practice session, an additional survey was administered to assess faculty participants' satisfaction with the JTFD program. Three items prompted faculty to reflect on their experiences in the JTFD program and responded to four statements on a 4-point Likert scale from strongly disagree to strongly agree. The average score for each item is reported below in table 9.

Table 9

Final CoP Survey to Measure Satisfaction with JTFD Program (out of 4)

\begin{tabular}{|l|c|}
\hline Statement & $\begin{array}{c}\text { Average } \\
\text { Score }\end{array}$ \\
\hline $\begin{array}{l}\text { The tools, strategies, and interaction I experienced throughout the JTFD } \\
\text { project will be of value to my future instructional practice and career } \\
\text { success. }\end{array}$ & 3.75 \\
\hline $\begin{array}{l}\text { The JTFD project has been successful in creating a Community of } \\
\text { Practice which supports innovation, implementation, and open dialogue } \\
\text { between colleagues. }\end{array}$ & 3.6 \\
\hline $\begin{array}{l}\text { I would recommend participation in the JTFD program to other } \\
\text { colleagues. }\end{array}$ & 3.65 \\
\hline
\end{tabular}

The first item asked respondents to report if they thought that the tools, strategies, and interactions from the JTFD program would benefit their future instruction and career. Participants had an average score of 3.75 on this item, indicating strong satisfaction with the 
JTFD program. Next, respondents reported an average score of 3.6 that the JTFD program successfully created a Community of Practice. Lastly, $100 \%$ of participants reported that they would recommend participation to the JTFD program to other colleagues (average score of 3.65). Ultimately, these three items indicate that faculty participants had both high satisfaction with and value of the JTFD program.

\section{Conclusion}

The JTFD program is a large-scale professional development program at a southwestern university in the United States. The program engaged over 80 faculty across 7 different engineering disciplines. Through workshops, communities of practice, and continuing communities of practice, faculty had opportunities and space to learn about student-teaching practices, discuss these innovations, and work on implementing these own practices into their classrooms. By creating an innovative and adaptable professional development program, the principal investigator team successfully engaged promoted the use of evidence-based instructional strategies of active learning to engineering faculty.

Through multiple and diverse evaluation methods, the principal investigator team gained deep insight into faculty's attitudes towards active learning teaching strategies, classroom practices, and value of the JTFD program. At the conclusion of the third year, program evaluation indicates successful implementation of the JTFD program. Average use of active learning strategies increased $13 \%$ from the start to the end of the program. Further, faculty reported a $34 \%$ average increase in use of formative feedback in their instructional practices, which is a critical practice to facilitate a flexible, interactive, and ongoing learning environment for students. Two major goals of the program were achieved through increasing awareness and transforming use of active learning strategies in engineering classrooms. Finally, we also sought to create sustainable environments and groups where faculty members could have ongoing conversations about their pedagogical practices and teaching strategies in the classroom. This is a critical piece to creating and fostering long-term and sustainable change in instructional strategies. Lastly, $100 \%$ of faculty participants reported that they felt the JTFD program would be of value to their future instructional practices/career success and that they would recommend this program to their colleagues. Ultimately, program evaluation indicates that the JTFD program successfully shifted faculty awareness of, attitudes towards, and use of active learning pedagogical practices in engineering classrooms.

\section{Acknowledgment}

The authors gratefully acknowledge support of this work by the National Science Foundation under Grant No. 1524527.

\section{References}

[1] Prince, M. (2004). Does Active Learning Work? A Review of the Research. Journal of Engineering Education, 93(3), 223-231. 
[2] Freeman, S., Eddy, S. L., McDonough, M., Smith, M. K., Okoroafor, N., Jordt, H., \& Wenderoth, M. P. (2014). Active learning increases student performance in science, engineering, and mathematics. PNAS, 11(23), 8410-8415.

[3] Felder, R. M., \& Brent, R. (2005). Understanding student differences. Journal of Engineering Education, 94(1), 57-72. doi: 10.1002/j.2168-9830.2005.tb00829.x.

[4] Felder, R. M., \& Brent. R. (2016). Teaching \& learning STEM: A practical guide. San Francisco, CA: Jossey-Bass.

[5] Borrego, M., Froyd, J. E., Hall, T. S. Diffusion of engineering education innovations: A survey of awareness and adoption rates in US engineering departments. Journal of Engineering Education, 99(3), 185-207.

[6] Rogers, E. M. (2003). Diffusion of Innovations (5th ed.). New York: Free Press.

[7] Krause, S., Baker, D., Carberry, A., Alford, T., T., Ankeny, C., Brooks, B.J., Koretsky, M., Waters, C., Gibbons, B. (2015). Effect of Implementation of JTF Engagement and Feedback Pedagogy On Faculty Beliefs and Practice and on Student Performance. American Society for Engineering Education Conference.

[8] Bransford, J. D., Brown, A. L., \& Cocking, R. D. (1999). How people learn: Brain, mind, experience, and school. Washington, DC: National Academy Press.

[9] Krause, S., Baker, D., Carberry, A., Alford, T., T., Ankeny, C., Brooks, B.J., Koretsky, M., Waters, C., Gibbons, B. (2015). Effect of Implementation of JTF Engagement and Feedback Pedagogy On Faculty Beliefs and Practice and on Student Performance.

American Society for Engineering Education Conference.

[10] Pimmel, R., and McKenna, A. (2014). Sponsored Session M464A, Faculty development using virtual communities of practice. 2014 ASEE Annual Conference Proceedings.

[11] Felder, R. M., \& Brent. R. (2016). Teaching \& learning STEM: A practical guide. San Francisco, CA: Jossey-Bass.

[12] Judson, E., Ross, L., Middleton, J. A., \& Krause, S. J. (2017). Measuring engineering faculty views about benefits and costs of using student-centered strategies. International Journal of Engineering Pedagogy, 7(2), 65-78.

[13] Piburn, M., Sawada, D., Falconer, K., Turley, J. Benford, R., Bloom, I. (2000). Reformed Teaching Observation Protocol (RTOP). http://PhysicsEd.BuffaloState.Edu/AZTEC/rtop/RTOP_full/PDF.

[14] Lawson, A. E., Benford, R., Bloom, I., Carlson, M. P., Falconer, K. F., Hestenes, D. O., Judson, E., Piburn, M. D., Sawada, D., and Wycoff, S. (2002). Reforming and evaluating college science and mathematics instruction. Journal of College Science Teaching, 31, 388-393.

[15] Sawada, D., Piburn, M. D., Judson, E., Turley, J., Falconer, K., Benford, R., and Bloom, I. (2002). Measuring reform practices in science and mathematics classrooms: The Reformed Teaching Observation Protocol. School Science and Mathematics, 102(6), 245253. 